\title{
UNA APROXIMACIÓN A LA FORMA DE INCUMPLIMIENTO \\ QUE DA LUGAR A LA GARANTÍA LEGAL EN LAS VENTAS \\ REGULADAS EN LA LEY SOBRE PROTECCIÓN \\ DE LOS DERECHOS DEL CONSUMIDOR*
}

\section{FranCisCa María BarRientos CAMUS**}

RESUMEN: Este trabajo intenta determinar a qué tipo de incumplimiento contractual debe reconducirse el supuesto de la garantía legal contemplada en los artículos 19 y 20 de la Ley No 19.496, de 1997, sobre Protección de los Derechos de los Consumidores. El texto examinará las tipologías que admite la inejecución de la obligación de entrega del Código Civil, para determinar la categoría de incumplimiento que activa la protección del consumidor por anomalías de las cosas.

PALABRAS CLAVE: Consumo - incumplimiento contractual - cumplimiento defectuoso - compraventa - remedios

\section{AN APPROXIMATION TO THE TYPE OF BREACH THAT GIVES WAY TO THE LEGAL GUARANTEE ON SALES REGULATED ON THE CHILEAN CONSUMER RIGHTS PROTECTION LAW}

ABSTRACT: This paper tries to determine to which type of breach of contract should be redirected the course of the legal guarantee provided in Articles 19 and 20 of Law No. 19,496 of 1997 on Protection of Consumer Rights. Throughout these pages, we will examine the distinct types of non-performance to deliver goods established by Civil Code, to determine what category of non-performance activates the consumer protection Law remedies for anomalies of goods.

Este trabajo se enmarca en el Proyecto Fondecyt regular No 1120548. El tratamiento de las entregas defectuosas en el derecho chileno: hacia una noción de incumplimiento amplia y unitaria.

Fecha de recepción: 12 de marzo de 2013.

Fecha de aceptación: 8 de octubre de 2013.

** Doctora en Derecho. Profesora de Derecho Civil, Universidad Diego Portales. Investigadora de la Fundación Fernando Fueyo Laneri, Dirección postal, República 112, 2º piso, Santiago, Correo electrónico: francisca.barrientos@mail.udp.cl 
KEY WORDS: Consumer law - breach of contract - defective performance - sales - remedies

Sumario: 1) Introducción. 2) El incumplimiento total: la falta de entrega. 3) El incumplimiento moratorio: la falta de entrega. 4) El cumplimiento imperfecto: la entrega con vicios. 4.1) Los vicios ocultos del producto. 4.2) El obligado a responder. 4.3) Los derechos que puede reclamar el comprador. 4.4) La procedencia de la indemnización de perjuicios. 4.5) El plazo de prescripción. Conclusiones.

\section{1) INTRODUCCIÓN}

El Párrafo $5^{\circ}$ del Título II de la Ley No19.496, de 1997, sobre protección de los derechos de los consumidores", denominado "Responsabilidad por incumplimiento", regula la garantía legal o derecho de opción, que contiene el sistema de responsabilidad civil contractual del vendedor. Solo se describe su supuesto de hecho y consecuencias jurídicas. Hay que señalar que no se trata de una regla infraccional, sino civil.

Para determinar la clase de inejecución de la LPDC se acudirá al derecho común en su carácter de general y subsidiario (artículo 2, 2 bis $^{2}$ y 4 del Código $\mathrm{Civil}^{3}$ ), con el objeto de revisar las categorías tradicionales que reconoce el artículo 1556 CC, para verificar si cabría la posibilidad de ser reconducida a alguna de ellas.

De este modo, se analizarán los incumplimientos totales que provengan de no haberse cumplido la obligación, los tardíos o moratorios, que nacen de haberse retardado el cumplimiento, y los incumplimientos imperfectos o defectuosos. Se estudiarán estas tipologías en el ámbito de la compraventa, en materia de entrega de la cosa. Todo ello, para determinar que el derecho de opción contiene un supuesto amplio y unitario de inejecución contractual.

\section{2) EL INCUMPLIMIENTO TOTAL: LA FALTA DE ENTREGA}

Se ha sostenido que esta modalidad del incumplimiento surge cuando no se cumple la obligación de entrega por parte del vendedor. En

En adelante LPDC o ley.

Desde ahora en adelante, si no se hace alusión a la normativa se entenderá que se trata de la LPDC.

3 En adelante CC. 
nuestro medio nacional, Fernando Fueyo 4 señaló que el incumplimiento total tenía lugar cuando la prestación no llega a cumplirse; o cuando se ha dejado de cumplir una prestación de responsabilidad (deber de custodia o cuidado); o en los casos en que se han elevado a la esencia elementos accidentales. En general, el incumplimiento es total si no se ejecuta la prestación en todas sus partes 5 .

Tomando en consideración esta idea, la falta de entrega supone que la cosa objeto de la venta no se ha entregado, o bien no se ha entregado todas sus partes. Bajo este esquema hay consentimiento: se formó un acuerdo en el precio y la cosa, y el vendedor no cumple. Con ello, el comprador puede exigir el cumplimiento o la resolución, con indemnización de perjuicios, según la regla del artículo 1826 CC.

A juicio de Arturo Alessandri ${ }^{6}$ estas acciones serían la reproducción del artículo 1489 del Código Civil. Sin embargo, hay que señalar que la identificación de estas normas no es tan absoluta, pues el artículo 1826 CC exige un juicio de reprochabilidad para configurar el incumplimiento, calificación que no hace el artículo 1489 CC. Por ello, Álvaro VIDAL ${ }^{7}$ entiende que la imputación que formulan los artículos 1826 y 1873 CC debe entenderse para la indemnización de perjuicios y no para la resolución o la pretensión de cumplimiento.

En efecto, el acreedor puede solicitar, a su arbitrio, el cumplimiento del contrato o la resolución, con una indemnización de perjuicios. La opción asegurada en los artículos 1489 y 1826 CC es de libre elección para el comprador. En este sentido, no sería correcto imponer una jerarquía en los remedios del acreedor. No obstante lo anterior, nuestra doctrina tradicional ${ }^{8}$ consideraba que si la obligación era de dar no dineraria, y si el vendedor aún podía cumplir, el acreedor deberá agotar todas las posibilidades de cumplimiento en naturaleza; y solo cuando se torne imposible, podría solicitar una indemnización compensatoria. Esta tendencia ha sido

4 Fueyo Laneri, Fernando (2004) Cumplimiento e incumplimiento de las obligaciones. Actualizado por Figueroa Yáñez, Gonzalo. Santiago: Editorial Jurídica de Chile, p. 253.

5 Abeliuk Manasevich, René (2010) Las obligaciones. $5^{a}$ edición actualizada y aumentada. Santiago: Editorial Jurídica de Chile, pp. 869-871.

6 Alessandri Rodríguez, Arturo (2003) De la compraventa y de la promesa de compraventa, tomo I volumen No 2. Santiago: Editorial Jurídica de Chile, p. 779. El mismo argumento se encuentra en parte de nuestra doctrina reciente, en López Díaz, Patricia (2010) "La indemnización compensatoria por incumplimiento de los contratos bilaterales como remedio autónomo en el derecho civil chileno". Revista Chilena de Derecho privado, No 15, p. 71.

7 Vidal Olivares, Álvaro (2007b) "El incumplimiento de obligaciones con objeto fungible y los remedios del acreedor afectado. Una relectura de las disposiciones del 'Código Civil' sobre incumplimiento". Editor científico Alejandro Guzmán Brito. El Código Civil de Chile (1855-2005). Editorial LexisNexis: Santiago, nota al pie No 115, p. 537.

8 Entre otros, Claro Solar, Luis (1937) Explicaciones de Derecho Civil chileno y comparado, t. XI De las obligaciones II. Santiago: Editorial Nascimento, p. 692; Alessandri (2003) 779; Fueyo lo explica desde la perspectiva del deber de agotar los medios para obtener la ejecución de la obligación, FueYo (2004) 362; Abeliuk (2010) 853. 
abandonada por la doctrina moderna ${ }^{9}$, que no establece un orden de prelación.

Por su parte en el ámbito de consumo, la entrega de la cosa debe respetar los términos y condiciones del contrato conforme lo prescribe el artículo 12, pero tomando en consideración que se trata de una regla infraccional y no civil. Por integración con las reglas generales, debe realizarse cómo se pactó en el contrato (artículo 1828 CC), siempre y cuando no genere un desequilibrio importante de sus prestaciones, ya que podría dar lugar a una cláusula abusiva (artículo 16 letra g) contraria a las exigencias de la buena fe (artículo 1546 CC).

La ley no regula lo que sucede cuando no se entrega la cosa. Lo único que se sabe es que el proveedor debe cumplir con los términos y condiciones del contrato (artículo 12) y no puede negar injustificadamente la venta (artículo 13). Como se trata de normas infraccionales, si se infringen nacerá para el proveedor una sanción traducida en multas a beneficio fiscal, contemplada en el artículo 26.

Asimismo, y con el objeto de reafirmar lo que se dice, en algunas sentencias de los jueces de Policía Local y Cortes de Apelaciones es posible encontrar ejemplos acerca de falta de entrega, pero que no dicen relación con la garantía legal. En este sentido, en Méndez con París S.A. ${ }^{10}$ la consumidora compró un dispositivo musical de reproducción digital (mp3) a través de medios electrónicos, que seis días más tarde la empresa

9 Entre otros, Barros Bourie, Enrique (2008) "Finalidad y alcance de las acciones y remedios contractuales”. Editor científico Alejandro Guzmán Brito. Estudios de Derecho Civil III. Santiago: LegalPublishing, pp. 403-428; Vidal Olivares, Álvaro (2007a) "La pretensión de cumplimiento específico y su inserción en el sistema de remedios por incumplimiento en el Código Civil". Coordinadores Hernán Corral y María Sara Rodríguez. Estudios de Derecho Civil II. Santiago: LexisNexis, pp. 517-538, Vidal Olivares, Álvaro (2011) "La indemnización de daños y la opción del acreedor frente al incumplimiento". Coordinadores Gonzalo Figueroa Yáñez et alii. Estudios de Derecho Civil VI. Santiago: Editorial Abeledo Perot LegalPublishing, pp. 763-780, y Vidal Olivares, Álvaro (2009) "La noción de incumplimiento esencial en el 'Código Civil'”. Revista de Derecho, XXXII, pp. 221-258; Pizarro Wilson, Carlos (2008) "Hacia un sistema de remedios al incumplimiento contractual”. Editor científico Alejandro Guzmán Brito. Estudios de Derecho Civil III. Santiago: LegalPublishing, pp. 395-402; De la Maza Gazmuri, Ińigo (2011) "El concurso entre el error con transcendencia anulatoria y el incumplimiento resolutorio". Coordinador Ińigo de la Maza. Incumplimiento contractual. Nuevas perspectivas. Cuadernos de análisis jurídicos. Colección de Derecho Privado VII, Santiago: Ediciones Universidad Diego Portales, pp. 213-234: Mejías Alonzo, Claudia (2011) El incumplimiento resolutorio en el Código Civil. Santiago: Editorial AbeledoPerrot-LegalPublishing; Bahamondes Oyarzún, Claudia (2011) "Concurrencia de la indemnización de perjuicios de daños y la pretensión de cumplimiento específico frente al incumplimiento". Coordinador Iñigo de la Maza. Incumplimiento contractual. Nuevas perspectivas. Cuadernos de análisis jurídicos. Colección de Derecho Privado VII, Santiago: Ediciones Universidad Diego Portales, pp. 235-264; López (2010) 65-113.

10 Corte de Apelaciones de San Miguel, 10 de mayo de 2011, Rol No 195-2011, LegalPublishing No 49281, "Méndez con París S.A.”, disponible en www.westlaw.cl [fecha de visita 01 de marzo de 2013]. 
proveedora le comunicó que no tenía stock, aunque en la página web no se indicó que la oferta estaba sujeta un número determinado. La Corte, para condenar a la proveedora, acudió a las reglas propias de la ley de consumo, en particular a los artículos 3 letra b), 23, 33 y 35, razonamiento que se basa en las condiciones de las promociones y la infracción al deber de información. Así se condenó al pago de una multa de 30 UTM a beneficio fiscal, con costas. No se sabe si hubo indemnización de perjuicios, ya que la sentencia solo reseña la multa infraccional.

En San Martín, Sernac con ABC Din ${ }^{11}$ también se trató de la falta de una promoción que venía incluida con la venta principal. En este caso, el consumidor adquirió un televisor tipo LCD que contemplaba una promoción de entrega de un juego denominado coloquialmente como "taca taca”; además, por tratarse de la primera compra en el establecimiento comercial, tenía derecho a un descuento del 10\%. En este caso se configuraba una promoción y oferta a la vez, en los términos de la LPDC. Según se describe en la sentencia, cuando el consumidor acudió a hacer efectiva la promoción, le informaron que no tenía derecho a ella, ya que se había hecho efectivo el descuento (oferta) y ambas eran incompatibles. Por esta razón, el consumidor decidió demandar en virtud de las reglas de consumo por publicidad engañosa. De este modo, se condenó en primera instancia al pago de $\$ 70.000$ por concepto de daño directo, $\$ 100.00$ daño moral y un multa de 30 UTM, que fue rebajada por la Corte de Coyhaique. En este caso operó una indemnización compensatoria junto con el daño moral y una condena infraccional fundada en base a lo dispuesto en los artículos 3 letra e) y 23. Este tema hace pensar en la vinculación que tienen las promociones y ofertas con el producto principal. En este ejemplo, la falta de entrega no es referida a la cosa misma, sino que a la promoción. Con todo, no se entregó el bien promocionado, lo que produce la falta de entrega, la cual debe hacerse con todos sus frutos y accesorios conforme lo ordenan las reglas geenerales (artículos 1829 y 1830 CC).

Junto con ello, cabe señalar que se ha aplicado el artículo 13 LPDC para exigir judicialmente la entrega de la cosa vendida. Así, en Campos con Dell computer de Chile Ltda. ${ }^{12}$, el demandante visitó la página web de la empresa Dell, que ofrecía computadores portátiles a muy bajo precio. Luego de haber seguido los pasos electrónicos para efectuar la compra, la empresa se negó a entregarlos alegando falta de oferta o error en

11 Corte de Apelaciones de Coyhaique, 05 de mayo de 2011, Rol No 8-2011, LegalPublishing No 49328, "San Martín, Sernac con ABC Din", disponible en www.westlaw.cl [fecha de visita 05 de marzo de 2013].

12 Corte de Apelaciones de Santiago, 12 de marzo de 2012, Rol No 8470-2010 y Juzgado de Policía Local de Vitacura, 11 de noviembre de 2009, Rol No 114.876 “Campos con Dell computer de Chile Ltda.", disponible en www.poderjudicial.cl [fecha de visita 08 de marzo de 2013]. 
el precio de la compraventa. Por esta razón, dicho comprador, invocando una representación a favor de su empresa, se querelló y demandó exigiendo una indemnización de perjuicios y la entrega de los tres notebook comprados $^{13}$. Por su parte, la Corte de Apelaciones de Santiago confirmó el fallo de primera instancia que acogió sus acciones, en circunstancias que el comprador accionó como una empresa, lo que estaría fuera del ámbito protector de la ley. Por esto, sería posible cuestionar la calificación de consumidor como querellante y demandante, toda vez que actuaba en representación de su empresa ${ }^{14}$. Además, contrario al parecer de la Corte, la venta parece injustificada, lo que podría argumentarse como una práctica contraria a la buena fe (ex artículo 16 letra g), o una oferta sujeta a reserva $^{15}$, porque parece discutible que los computadores portátiles se ofrecieran a un precio de $\$ 30.000$ aproximadamente cada uno y que el demandante quisiera adquirir tres para su empresa y no para uso familiar, doméstico o familiar.

Entonces, en sede de consumo, para que nazcan los derechos irrenunciables de la garantía legal, es necesario que, al menos, se haya efectuado la entrega de la cosa. Si no se cumple con ello, no correspondería aplicar estas normas. Por esta razón, no sería posible reconducir esta forma de incumplimiento hacia las reglas civiles que disciplinan la no entrega de la cosa, toda vez que el supuesto de hecho es diferente. Bajo estas normas (de consumo) ha principiado la entrega, pero con ciertas anomalías de cantidad, calidad, seguridad, especificaciones e incluso algunas declaraciones publicitarias que inciden en las decisiones del consumidor ${ }^{16}$.

En definitiva, se aprecia que la falta de entrega no se acerca al supuesto de hecho que activa la garantía legal, ni desde el derecho común, ni en los fallos o incluso en las mismas disposiciones de la ley. El derecho de opción exige la entrega de la cosa aunque defectuosa, mientras que la inejecución que regula el CC, simplemente no hay entrega. Por lo anterior, la forma de incumplimiento que supone la inejecucion total de la

13 En los hechos, el consumidor describió que siguió todos los pasos del proceso de compra electrónica, adquirió al precio de \$109.853 los tres ordenadores que pagó mediante transferencia bancaria, luego apareció la orden de compra con un número determinado y para finalizar recibió un correo de confirmación que agradecía la compra.

14 La LPDC exige que los consumidores no sean proveedores. Así, el artículo 1 No 1 lo expresa en términos que en ningún caso podrán ser considerados consumidores los que de acuerdo al número siguiente deban entenderse como proveedores.

15 Así lo propone De la Maza Gazmuri, Iñigo (2009) “Ofertas sujetas a reserva: a propósito de los términos y condiciones en los contratos celebrados por medios electrónicos”. Revista de Derecho. Volumen XXII. Año N², pp. 75-95.

16 Además, desde el punto de vista de los remedios, la LPDC presenta un formato diverso. Si se atiende a la descripción que efectúan sus normas, podría encontrarse ciertas coincidencias con el artículo 20, pero no con el 19, que no contempla la indemnización de perjuicios, pero entrega la posibilidad de rebajar el precio. 
obligación, o para estos efectos la falta de entrega de la cosa, se aleja de los problemas de la garantía legal.

No obstante lo anterior, hay una modalidad de falta de incumplimiento que sí adquiere importancia. Se trata de la institución conocida como aliud pro alio o entrega de una cosa diversa a la pactada, en que el comprador recibe una cosa diversa según los términos y condiciones del contrato, ya sea material (aliud, material), o una cosa inhábil para las pretensiones del acreedor (aliud, funcional) ${ }^{17}$.

En el texto civil codificado no se encuentra un reconocimiento expreso de esta institución. Por eso, hasta el momento se conocen dos ${ }^{18}$ sentencias actuales de la Corte Suprema que lo tratan de manera diversa, ya sea como una falta de entrega o como un cumplimiento imperfecto, aplicándole diversos remedios. El primero, caratulado Cecinas La Preferida con Comercial Salinak ${ }^{19}$, la demandante persiguió la resolución del contrato de compraventa, y en subsidio la rescisión del mismo, por afectarle un vicio redhibitorio más indemnización de perjuicios. En los hechos, la empresa demandada se comprometió a entregar sal nitrificada al 0,8\%, que resultó ser sal de cura que, además, contenía una concentración de 8\%. El segundo, es el caso denominado Zorín S.A. con Compañía Side-

17 De Verda y Beamonte, José Ramón (2009) Saneamiento por vicios ocultos. Las acciones edilicias, 2a edición. Navarra: Editorial Aranzadi-Thomson Reuters, p. 259.

18 En realidad son tres, pero la tercera se relaciona con el saneamiento de la evicción y la concepción de la entrega material del inmueble gravado con hipoteca. En Transportes Sierra Nevada con Dosque, la actora reclamaba una entrega inexacta debido a la existencia de hipotecas y prohibiciones de gravar, enajenar y arrendar inscritas que no se ajustaban con una cláusula de la compraventa que establecía que la venta se hacía libre de gravámenes. Así, demanda el cumplimiento de la obligación, es decir, la entrega de la cosa y el alzamiento de los gravámenes y prohibiciones, junto con una indemnización de perjuicios. La Corte de Concepción hizo una reflexión de lo que comprende la obligación de entrega y llega a la conclusión que no puede entenderse que existan dos entregas fraccionadas y desligadas entre sí (artículos 1824 y 1837). En su concepto lo que reza el contrato: ... hace de la obligación de entregar no solamente un paso material y jurídico de la cosa, sino que también comprender en ella, una identidad entre aquello que forma el objeto de la obligación y lo efectivamente entregado, puesto que, en definitiva, no se trata sino de la particularización de la regla general del articulo 1569 que impone como requisito objetivo del cumplimiento la exactitud, identidad e integridad de la prestación, pues guarda aún vigencia la fórmula del Derecho Romano aliud pro alio, invito creditori solvi non potest... (considerando $8^{\circ}$ ). Con todo, no da lugar a la acción por estimar que no es posible acceder a ella, ya que se encuentran involucrados derechos de terceros (banco acreedor hipotecario). Corte de Apelaciones de Concepción, 01 de diciembre de 1993, Rol No 1171-1992, LegalPublishing No 22097), “Transportes Sierra Nevada con Dosque", www.westlaw.cl [fecha de visita 08 de marzo de 2013]. Esta sentencia fue dictada por la Corte de Apelaciones de Concepción y redactada por el abogado integrante Ramón Domínguez Águila.

19 Corte Suprema, 27 de julio de 2005, Rol No 5320-2003, LegalPublishing 32452, “Comercial Salinak con Cecinas La Preferida", www.westlaw.cl [fecha de visita 10 de enero de 2013]. 
rúrgica Huachipato ${ }^{20}$, que se concibe como un cumplimiento imperfecto. En los hechos, la actora reclamó el incumplimiento de la entrega de mil quinientos rodillos de acero en desuso que no cumplían con la calidad ofrecida (cierta cantidad de níquel). Aquí no se demandó invocando las acciones edilicias, sino que solo una indemnización de perjuicios de carácter autónoma, sin acompañarla de la pretensión de cumplimiento o la resolución, que fue otorgada por el tribunal. Y a diferencia de la sentencia anterior, se entendió que la entrega diversa a la pactada constituía un cumplimiento imperfecto, pero diverso del saneamiento de los vicios redhibitorios, que da lugar a la indemnización de perjuicios autónoma. Entonces, como es posible ver, como el aliud pro alio supondría una clase de inejecución total por falta de entrega y también una forma de cumplimiento imperfecto o defectuoso.

Dicho esto, conviene señalar que el aliud pro alio encontraría cabida en las disposiciones que trata la garantía legal en la LPDC. En concreto, en la regulación sobre las "faltas de especificaciones" en las normas de cumplimiento obligatorio (artículo 20 letra a), la "falta de especificaciones" en las menciones que ostente el rotulado (artículo 20 letra b) y la "falta de especificaciones" convenidas con el consumidor (artículo 20 letra d). Si se analiza con detención, en estos supuestos de "falta de especificaciones" se entrega un producto que no contiene las especificaciones requeridas por la autoridad correspondiente, por las declaraciones que emite el proveedor o las consensuadas con el consumidor, que suponen un incumplimiento total de la obligación de entrega. Así, Hernán CoRRAL $^{21}$ lo ha tratado como una clase de incumplimiento y no como un vicio redhibitorio.

20 Corte Suprema, 31 de octubre de 2012, 3325-2012, cita Westlaw CL/JUR/2412/2012, Zorín S.A. con Compañía Siderúrgica Huachipato", www.westlaw.cl [fecha de visita 10 de enero de 2013].

21 En efecto, el profesor Hernán Corral ha efectuado diversos tratamientos doctrinarios sobre la garantía legal, que podrían sistematizarse en dos etapas. En un primer momento distinguió entre: $1^{\circ}$ incumplimiento en el producto de las debidas especificaciones (artículo 20 letras a, b, d, g y artículo 19); $2^{\circ}$ ineptitud del producto para el uso al cual se le destina (artículo 20 letras c, e y f). Respecto del primero, sugiere que serían supuestos de incumplimientos resolutorios contractuales y los segundos de vicios redhibitorios, en Corral TALCIANI, Hernán (1999) "Ley de protección al Consumidor y responsabilidad civil". Editor Hernán Corral. Derecho del consumo y protección al consumidor. Estudios sobre la Ley No 19.496 y las principales tendencias extranjeras. Cuadernos de Extensión Jurídica No 3. Santiago: Ediciones Universidad de los Andes, p. 173. Luego, efectuó otra clasificación en tres grupos: $1^{\circ}$ incumplimiento de las especificaciones (artículo 20 letras $a, b$ y d); $2^{\circ}$ deficiencias o falta de cualidades que determinan la ineptitud del producto (artículo 20 letras c, e y f); y $3^{\circ}$ diferencias entre el contenido real y el contenido indicado (artículos 19 y 20 letra g), en Corral Talciani, Hernán (2006) La responsabilidad por incumplimiento y por productos peligrosos en la ley de protección de los derechos de los consumidores. Editores Jorge Baraona y Osvaldo Lagos. Cuadernos de extensión Juridica. La protección de los derechos de los consumidores en Chile. Aspectos sustantivos y procesales luego de la reforma contenida en la Ley $N^{\circ} 19.955$ de 2004, N¹2, Santiago: Ediciones Universidad de los Andes, p. 97. 
Por este motivo, si se estima que las faltas de especificaciones constituyen entregas diversas a las pactadas, podría sostenerse la admisión de una clase especial de inejecución total bajo el sistema de incumplimiento de la garantía legal. Con todo, hay que recordar que la regulación del derecho de opción no se agota en ellas. Hay otros vicios adicionales a las faltas de especificaciones, como los vicios ocultos (artículo 20 letra f), la vinculación publicitaria (artículo 20 letra c) o las anomalías de cantidad (artículo 19). Además, los remedios que entregan no consideran la rebaja del precio que forma parte del sistema. Por ello, puede sostenerse que la correspondencia no sería plena.

En suma, la falta de entrega, que podría denominarse material, no concuerda con el supuesto de hecho del derecho de opción, mientras que la entrega diversa a la pactada sí. Esto permite sostener que faltaría otra tipología que lo complemente. Para determinar esto, a continuación corresponde examinar el incumplimiento moratorio o entrega tardía.

\section{3) EL INCUMPLIMIENTO MORATORIO: LA ENTREGA TARDÍA}

El incumplimiento moratorio se produce cuando no se ha satisfecho al acreedor en tiempo oportuno. En el ámbito de la entrega, esta clase de incumplimiento tiene lugar en los casos que el vendedor retrasa la entrega de la cosa. Entonces, el incumplimiento moratorio surge cuando se entrega la cosa en tiempo oportuno, sea el pactado por las partes o desde que se hizo exigible la prestación.

Jorge BARAONA ${ }^{22}$ distingue entre el retraso y la mora, y sostiene que para exista retraso debe existir la posibilidad de cumplir in natura. Aplicado a la compraventa, debería retrasarse la entrega de la misma cosa vendida, sin tomar en consideración la existencia de vicios o anomalías ${ }^{23}$.

De lo anterior, es posible colegir que los problemas que regula la garantía legal no se vinculan con el retraso en el cumplimiento de la obligación. El derecho de opción supone la entrega de una cosa con anomalías, no retrasada, aunque además podría serlo. Por esta razón, esta clase de incumplimiento se aleja de la idea de la garantía legal.

Dicho de otra forma, la LPDC no regula qué sucede cuando la cosa se entrega de forma tardía. Los casos de los artículos 19 y 20 ley suponen

22 Baraona González, Jorge (2008) "Algunas consideraciones sobre el retraso en el cumplimiento de las obligaciones: su configuración y eficacia". Coordinador Carlos Pizarro Wilson. Estudios de Derecho Civil IV. Santiago: Editorial LegalPublishing, pp. 372-374.

23 El retardo anterior a la calificación de la mora, se aplicaría a las ventas de especies o cuerpos ciertos. Así cumpliría la función de determinar el estado de transitoriedad e incertidumbre; y por ende, su distinción con la inejecución. En cambio, si se trata de obligaciones de género, por su propia configuración (la sustitución que presentan dentro de otras del mismo género), se confundiría con mora del deudor dando paso de inmediato al incumplimiento. 
que la cosa se ha entregado, pero de manera defectuosa. Si la entrega de la cosa de consumo masivo es retardada o moratoria, el consumidor tendría derecho a solicitar una indemnización de perjuicios, al igual que en el CC. La única norma que se refiere a ello es el artículo 3 letra e), que reconoce el derecho irrenunciable del consumidor a la indemnización de los dańos patrimoniales y morales. No trata el supuesto de la mora en particular.

Solo se conocen casos de entregas tardías específicamente en el ámbito de las sentencias de consumo de servicios, las que por analogía podrían ser aplicadas a los productos. Así por ejemplo, en el caso caratulado como Morales con Homecenter Sodimac ${ }^{24}$ se condenó a una multa e indemnización al proveedor por los perjuicios sufridos por la demora en el servicio contratado. En los hechos, la demandante (y denunciante) contrató un servicio de pintura para su casa que demoró tres meses en vez de una semana, y mientras tanto se seguían cargando las cuotas por el servicio no realizado. Por este motivo, la Corte de Apelaciones de Antofagasta revocó la sentencia de primera instancia que ordenaba la realización de los trabajos y servicios contratados, porque se demostró su ejecución. De todos modos, aclaró que se configuró una infracción al artículo 23, porque el proveedor actuó con "notoria negligencia" en la prestación del servicio, provocándole un menoscabo al consumidor (considerando $7^{\circ}$ ).

En en el fallo Vergara con Empresa de Correos de Chile ${ }^{25}$ la demandante y denunciante contrató los servicios para enviar una encomienda que fue entregada con doce días de atraso, por un servicio que debió demorar un día. En este caso, se discutía el ámbito de aplicación de la ley para Correos de Chile, que cuenta con una regulación especial ${ }^{26}$. La Corte sostuvo que, como las normas que regulan el servicio de correos no tratan el supuesto específico de la entrega tardía, era procedente la acción bajo las normas y procedimiento del consumidor. Por ello, rechazó la excepción incompetencia y ordenó al juez de Policía Local seguir conociendo estos antecedentes hasta el pronunciamiento de la sentencia definitiva.

En suma, tal como se ha analizado esta tipología, es posible sostener que tampoco coincide con el régimen de incumplimiento que otorga la garantía legal. De este modo, corresponde examinar la noción de cumplimiento imperfecto y los vicios redhibitorios, para estimar si se ajusta a la forma de incumplimiento que da lugar al derecho de opción.

\footnotetext{
24 Corte de Apelaciones de Antofagasta, 29 de octubre de 2008, Rol No 107-2008, LegalPublishing No 40448, "Morales con Homecenter Sodimac", www.westlaw.cl [fecha de visita 10 de enero de 2013].

25 Corte de Apelaciones de Arica, 16 de abril de 2011, Rol No 14-2011, LegalPublishing No 49244, "Vergara con Empresa de Correos de Chile", www.westlaw.cl [fecha de visita 10 de enero de 2013].

26 Cfr. artículo 2 bis LPDC.
} 


\section{4) EL CUMPLIMIENTO IMPERFECTO: LA ENTREGA CON VICIOS}

El estudio de esta modalidad supone que se entrega la cosa, pero de manera imperfecta. Se trata, entonces, de un caso en que el deudor realiza una prestación que no es adecuada o inexacta para satisfacer al acreedor. En nuestro medio nacional, Fernando Fueyo ${ }^{27}$ explicaba que había apariencia de cumplimiento, pero insuficiente para dar por liberado al deudor. Por su parte, René Abeliur ${ }^{28}$ estima que se trata de un incumplimiento parcial, que no se cumple de forma íntegra.

El cumplimiento parcial o imperfecto no es sinónimo de defectuoso. Caben dentro de él, la prestación defectuosa por los problemas de cabidas (artículo 1832 CC), el saneamiento de la evicción sea total o parcial (artículos 1838, 1852, 1853 y 1854 CC), y por cierto, los vicios redhibitorios (artículo 1858) ${ }^{29}$. Estas reglas particulares reflejan la disparidad normativa y casuística de estos regímenes. Cada uno contempla un ámbito específico, con acciones propias de corto tiempo (un año o incluso meses), en circunstancias que las reglas generales (artículos 1826 y 1489) ofrecen el plazo de prescripción general de cinco años para la acción de cumplimiento, resolutoria o indemnizatoria.

Si se piensa en la regulación de la garantía legal de la ley de consumo, hay que señalar que el artículo 20 letra f) exige la presencia de vicios ocultos. Por este motivo, es necesario dirigir el estudio a los vicios ocultos del Código Civil. En este orden de ideas, conviene señalar que para Arturo Alessandri se trataban de vicios redhibitorios los que, existiendo al tiempo de la venta y no siendo conocidos por el comprador, hacen que la cosa sea impropia para su uso natural o que solo sirva imperfectamente $e^{30}$. Con esta definición se ponía el acento en la idea del uso natural, que describe los elementos de los vicios del artículo $1858 \mathrm{CC}$, sobre todo la gravedad.

El literal f) del artículo 20 no hace mención a la gravedad. Con todo, el literal b) del mismo artículo contiene una descripción amplia que supone que el producto no es enteramente apto para el uso o consumo a que está destinado, que se relacionaría con la gravedad. Esta disposición hace alusión a la destinación de las cosas para el uso o consumo, cuya tipificación no coincidiría con la exigencia del uso natural del CC, ni tampoco con el vicio oculto del literal f), ya citado.

FueYo (2004) 254.

Aвeliuk (2010) 794.

De la Maza Gazmuri, Iñigo (2012) "El régimen de los cumplimientos defectuosos en la compraventa". Revista chilena de Derecho privado. Volumen 39, No 3, pp. 629-663.

Alessandri (2003) 186. 
En términos generales, Hernán Corral ${ }^{31}$ considera que el fundamento de la garantía legal se encontraría en los vicios redhibitorios, pero que esta coincidencia no sería plena. Para ello, realiza un estudio sobre ambas instituciones desde diversos puntos de vista, que serán examinados a continuación. Siguiendo las divergencias que observa este autor, se verá a) el carácter oculto del vicio, b) el sujeto responsable, c) los derechos que pueden reclamarse, e) la procedencia de la indemnización de perjuicios, y e) los plazos de prescripción.

\section{1) LOS VICIOS OCULTOS DEL PRODUCTO}

Que el vicio sea oculto quiere decir que el comprador lo haya ignorado al tiempo del contrato. El artículo 1858 No 3 CC contiene esta exigencia en términos que no haberlos manifestado el vendedor, y ser tales que el comprador haya podido ignorarlos sin negligencia grave de su parte, o tales que el comprador no haya podido fácilmente conocerlos en razón de su profesión u oficio. El desconocimiento del vicio por parte del comprador es un requisito para la configuración del vicio, sin la cual no existe la anomalía. Si el comprador lo conocía o estaba en condiciones de conocerla, aun cuando el bien presente taras, no se genera el saneamiento de la entrega. El CC estableció una regla de atribución de los riesgos acerca de la información que poseen las partes, cada uno tiene (o debería tener) la misma posibilidad de acceso al conocimiento sobre el estado y cualidades de las cosas.

Lo expresado marca una diferencia con las exigencias del vicio en el ámbito del consumo. El consumidor no estaría en la misma posición que el proveedor para conocer el bien. Por ello, los vicios serían más amplios que los regulados en el ámbito civil. En este sentido, Hernán Corral $^{32}$ sugiere que el concepto de vicio de consumo satisface solo con que no sea apto para el uso o consumo (artículo 20 letra c). O sea, no sería oculto.

No obstante, hay que señalar que el artículo 20 letra f) sí contempla esta exigencia al señalar que el vicio debe ser oculto. La ocultación del vicio sí sería un requisito general en el consumo, aun cuando solo se encuentre regulado en el literal $\mathrm{f}$ ), pero con la particularidad que el consumidor comprador de la cosa no puede conocer el desperfecto del producto, por la asimetría de información (y negociación) que justifica la existencia de esta regulación particular. Entonces, se presentaría una primera diferencia entre estas instituciones. Si bien es cierto, ambos estatutos exigen la ocultación del vicio, hay que señalar que en el ámbito

\footnotetext{
31 Corral (1999) 182 y ss. salvo los casos de faltas de especificaciones obligatorias, ofrecidas o convenidas, los cuales podrían integrar el régimen general de incumplimiento o incluso una clase de nulidad por error esencial.

32 Corral (1999) 182.
} 
de consumo no se aplica la posibilidad de conocimiento que recoge en el CC, en el sentido que conociendo el vicio no lo hubiera comprado o comprado a mucho menos precio (artículo 1858).

A continuación se analizarán las divergencias desde el punto de vista del sujeto obligado.

\section{2) EL OBLIGADO A RESPONDER}

En materia civil, el vendedor será siempre el sujeto obligado al saneamiento de los vicios redhibitorios. Por esto que un tercero ajeno al contrato de compraventa no podría ser el sujeto pasivo de la acción edilicia, pues ello atentaría contra el principio de efecto relativo del contrato consagrado en el artículo 1545 CC.

Hay un caso en que se negó el saneamiento de los vicios redhibitorios al comprador que demandó al cesionario del vendedor. En Aravena con Comercial Rupanco Limitada e Inversiones San Ignacio S.A. ${ }^{33}$ se rechazó la acción redhibitoria impetrada contra el cesionario, porque la Corte de Apelaciones de Rancagua consideró que el saneamiento era una obligación inherente al vendedor que no era cesible. Para negarlo señaló que: [S] in embargo, la obligación de sanear los vicios redhibitorios es inherente al vendedor, segun se desprende de la ubicación que se le ha asignado a esta materia dentro de la normativa sobre contrato de compraventa, la cual aborda como una de las obligaciones del vendedor, cual es, el saneamiento de la cosa vendida. De esta forma, responderán también del saneamiento de los vicios redhibitorios los herederos y donatarios universales del vendedor, por ser sucesores en los derechos y obligaciones del causante; pero no están obligados a sanear estos vicios, entre otros, los cesionarios del vendedor, sin perjuicio del derecho del comprador para abstenerse del pago adeudado, si sorprende un vicio en la cosa vendida de aquellos que puedan constituirse como redhibitorios (considerando $1^{\circ}$ penúltima parte). Esta idea, que se encuentra en el texto de Arturo Alessandri ${ }^{34}$, que restringe el saneamiento al comprador cuando el vendedor cede sus derechos, por una aplicación extensiva del artículo $1841 \mathrm{CC}$ en materia de evicción.

De este modo, en sede civil, el vendedor solo puede ser el sujeto pasivo de la acciones de saneamiento. Lo anterior, constituye una diferencia con la garantía legal, en que además del vendedor responden otros sujetos

\footnotetext{
33 Corte de Apelaciones de Rancagua, 21 de octubre de 2008, Rol No 828-2007, LegalPublishing No 38231, "Aravena con Comercial Rupanco Limitada e Inversiones San Ignacio S.A.”, www.westlaw.cl [fecha de visita 20 de enero de 2013]. En todo caso, la Corte revocó el fallo de primera instancia en la parte que acogió la acción redhibitoria como resolutoria, y declaró, que el contrato de compraventa estaba rescindido por efectos de la nulidad. Alessandri (2003) 218.
} 
que participan en la cadena de comercialización del bien de consumo masivo.

En efecto, la misma ley reconoce que el consumidor puede accionar contra otros agentes. El inciso $2^{\circ}$ del artículo 21 se refiere al caso que el consumidor opte por la reparación, facultando al consumidor para dirigirse contra el vendedor o el fabricante, indistinta o conjuntamente. Es decir, la ley atribuye una acción directa contra el fabricante por la subsanación de las cosas, que rompe la relatividad del contrato de compraventa. Dicho de otra forma, se permite que el acreedor extremo se dirija contra el vendedor de su vendedor, tomando en consideración una cadena de contratos ligados entre sí, haciendo aplicable el régimen de responsabilidad contractual ${ }^{35}$.

Asimismo, en materia de indemnización, la ley contempla que el consumidor acuda a otros agentes de la cadena del consumo, de manera solidaria o subsidiaria, según la norma que lo regule. El artículo 21 inciso $3^{\circ}$ establece que serán solidariamente responsables por los perjuicios ocasionados al consumidor, el proveedor que haya comercializado el bien o producto y el importador que lo haya vendido o suministrado. Así, el importador responde bajo un régimen de responsabilidad solidaria junto al vendedor. Por su parte, el inciso $5^{\circ}$ de la misma disposición consagra la responsabilidad subsidiaria de los agentes del consumo, al expresar que las acciones a que se refiere el inciso primero (el ejercicio de los derechos que contemplan los artículos 19 y 20 incluida la indemnización de perjuicios) podrán hacerse valer, asimismo, indistintamente en contra del fabricante o el importador, en caso de ausencia del vendedor por quiebra, término de giro u otra circunstancia semejante. Entonces, para los demás agentes habría un régimen subsidiario de responsabilidad, salvo para el importador que será solidario, que supone que primero se acude al vendedor y luego a los demás sujetos.

En este orden de ideas, desde el punto de vista del obligado también sería posible apreciar las diferencias que existen entre estas instituciones. En el sistema del CC responde única y exclusivamente el vendedor, a diferencia de lo que la misma ley reconoce al comprador de la cosa de consumo masivo. Esto demuestra un reconocimiento a las actuales formas de intercambio de los bienes y la conexión que existe entre los miembros de la cadena de distribución de los productos. Dicho esto, corresponde examinar los derechos o remedios que puede reclamar el sujeto activo.

35 Por ejemplo, se ve una configuración de esta institución en el texto de Figueroa YáÑEz, Gonzalo (2004) "El efecto relativo en los contratos conexos". Coordinadora María Dora Martinic, Nuevas tendencias del Derecho. Santiago: Editorial LexisNexis, p. 81; Pizarro Wilson, Carlos (2007) "El efecto relativo de los contratos: partes y terceros". Editor científico Alejandro Guzmán Brito. El Código Civil de Chile. Santiago: Editorial LexisNexis, 2007, pp. 551-567. 


\section{3) LOS DERECHOS QUE PUEDE RECLAMAR EL COMPRADOR}

Tal como se ha señalado, en el ámbito del consumo el comprador cuenta con cuatro remedios irrenunciables frente a las anomalías de las cosas: la reparación, la sustitución, la rebaja del precio y la resolución del contrato (que la ley llama devolución del precio), con indemnización de perjuicios, los cuales en cuanto a la amplitud de su ejercicio serían más eficaces que las tradicionales acciones edilicias.

Así expuestas las cosas, conviene señalar que el régimen de saneamiento del CC solo contempla la posibilidad de destruir de forma total o parcial el vínculo jurídico. Las acciones disponibles para el comprador afectado por el vicio de la cosa son: a) la redhibitoria, la cual se ha entendido como una resolutoria especial, con la salvedad que parte de la doctrina actual ha propuesto que tendría naturaleza anulatoria ${ }^{36}$, y b) la acción de rebaja del precio. Bajo estas reglas no hay remedios de cumplimiento.

En cambio, el derecho de opción del consumidor, como su nombre lo indica, concede la posibilidad de escoger de forma libre y voluntaria las medidas de cumplimiento (la reparación y la sustitución) y las de quiebre contractual (rebaja del precio y resolución del contrato), y además una indemnización de perjuicios.

En este sentido, se ve que en ellas se otorgan los mismos derechos del CC, pero además otros de gran eficacia para el adquirente. Por las actuales condiciones del tráfico, el consumidor quiere (o necesita) la cosa para destinarla a sus necesidades de consumo. La resolución, pese a que puede elegirse como primera opción, no siempre satisface los intereses del acreedor. Lo mismo podría ocurrir con la rebaja del precio, que no goza de aplicación práctica, porque en este ámbito las cosas son de fácil intercambio.

Así, en realidad, todo parece indicar que los artículos 19 y 20 LPDC, tratarían de un régimen que, en las palabras de Antonio Morales ${ }^{37}$, ha superado el incumplimiento del régimen de saneamiento de los vicios redhibitorios y las tradicionales acciones edilicias. Se contempla un tipo de

36 Baraona González, Jorge (2008) “La acción redhibitoria como acción de nulidad”. Editor cientifico Alejandro Guzmán Brito. Estudios de Derecho Civil III. Santiago: Editorial LegalPublishing, p. 660; Guzmán Brito, Alejandro (2007) "Sobre la relación entre las acciones de saneamiento de los vicios redhibitorios y las acciones comunes de indemnización, con especial referencia a la prescripción”. Revista chilena de Derecho Privado, No 9, p. 102.

37 Morales Moreno, Antonio Manuel (2006) "Adaptación del Código Civil al derecho europeo: la compraventa". La modernización del Derecho de las obligaciones. Madrid: Editorial Thomson Civitas, pp. 93-144; con la misma expresión, por ejemplo, Nieto Alonso, Antonia (2003) "La responsabilidad por vicios o defectos ocultos en las ventas. La superación de la rígida normativa del Código Civil como medio de defensa de los consumidores y usuarios". Comité organizador Antonio Cabanillas Sánchez et alii. Estudios jurídicos en homenaje al profesor Luis Diez-Picazo. Madrid: Editorial Thomson Civitas, p. 2701. 
incumplimiento amplio y unitario, con un sistema de remedios articulado en torno a ellos.

Para avanzar, ahora conviene examinar la procedencia de la indemnización de perjuicios.

\section{4) LA PROCEDENCIA DE LA INDEMNIZACIÓN DE PERJUICIOS}

Respecto de este tema, el profesor CoRRAL ${ }^{38}$ ha señalado como diferencia entre el derecho de opción y los vicios redhibitorios la procedencia la indemnización de perjuicios. En el ámbito del consumo la indemnización de perjuicios procedería siempre y sin restricciones cuando se verifiquen las condiciones para su interposición. Lo anterior, difiere de la ley civil, en que bajo una interpretación tradicional, el artículo 1861 CC exigía el conocimiento del vendedor (dolo), la que además era vista como una acción accesoria frente a las acciones edilicias.

Sin embargo, esta interpretación ha variado en el tiempo. Arturo Alessandri $^{39}$ apoyaba la idea de la accesoriedad y la exigencia del dolo. En cambio, en la actualidad, la doctrina ${ }^{40}$ y cierta tendencia jurisprudencial $^{41}$ ha ido aceptando que se indemnice todo dańo originado por el vicio redhibitorio de la cosa, especialmente el daño moral al reconducir la indemnización de perjuicios a las reglas generales de responsabilidad. Así las cosas, esta diferencia se ha matizado con el tiempo, aunque sirve como antecedente para confrontar estas instituciones.

Por último, queda verificar la situación de la prescripción de las acciones edilicias y de la garantía legal de consumo.

38 Corral (1999) 182

39 Alessandri (2003) 259. En realidad, Díez Duarte, Raúl (1993) La compraventa en el Código Civil chileno. 2da. edición actualizada. Santiago: Editorial Jurídica ConoSur, p. 170.

40 De la Maza Gazmuri, Ińigo (2010) “A propósito del artículo 1861". Editores Departamento de Derecho Privado Universidad de Concepción. Estudios de Derecho Civil V. Santiago: Editorial LegalPublishing, pp. 455-469.

41 En este sentido, Corte Suprema, 24 de mayo de 2007, Rol No 3140-2005, MJJ: 9854 , "Varela y otros con Servicio de Vivienda y Urbanismo I Región", www.microjuris.cl [fecha de visita 20 de enero de 2013]; Corte Suprema, 25 de julio de 2007, Rol No 6658-2007, LegalPublishing No 36814, "Spataris con Sociedad Comercial Automotriz La Portada con Luna" www.westlaw.cl, [fecha de visita 02 de marzo de 2013]; Corte Suprema, 8 de julio de 2010, Rol No 8115-2010, MJJ: 24291, "AGF Allianz Chile compañía de seguros generales S.A. con Le Torneau Inc.”, www.microjuris.cl [fecha de visita 20 de enero de 2013]; Corte Suprema, 25 de mayo de 2010, Rol No 5849-2008, MJJ: 24029, "Fernández con E. Kovakcs S.A.” www.microjuris.cl [fecha de visita 20 de enero de 2013]; Corte SupreMA, 27 de marzo de 2008, Rol No 6700-2006, LegalPublishing No 38680, "Larzabal con Sociedad Inmobiliaria Talasia Limitada", www.westlaw.cl, [fecha de visita 02 de marzo de 2013]; Corte Suprema, 14 de noviembre de 2006, Rol No 2265-2006, LegalPublishing No 35531, "Jara y varios con Sociedad inmobiliaria San Francisco Limitada" www.westlaw.cl, [fecha de visita 02 de marzo de 2013]. 


\section{5) EL PLAZO DE PRESCRIPCIÓN}

En relación al plazo de prescripción hay que señalar que la acción redhibitoria caduca en seis meses o un año, según si trata de acciones muebles o inmuebles (artículo $1866 \mathrm{CC}$ ); y la acción de rebaja del precio, en un año o dieciocho meses (artículo 1869 CC).

En sede de consumo, contrario a lo que podría esperarse, la protección del consumidor es más leve. El plazo para ejercer la garantía legal es de tres meses desde la entrega del producto. Incluso, puede ser de tan solo siete días, lo que merece severas críticas, si se trata de productos perecibles o que por su naturaleza estén destinados a ser usados o consumirse en plazos breves (artículo 21).

Estas diferencias demuestran que, a lo menos desde esta perspectiva, la noción de vicio redhibitoria sería más favorable que la LPDC.

En suma, lo que se ha denominado "vicio" de consumo se aprecia como más amplio que el vicio redhibitorio civil, sea en sus requisitos, el obligado a responder y los derechos o acciones. No puede decirse lo mismo de la prescripción, que tan solo se explica por defectos de técnica legal.

De este modo, no sería posible encasillar el supuesto de hecho que activa la protección dentro de alguna de las categorías clásicas del incumplimiento. Tal como se ha visto en este texto, la garantía legal puede reconducirse a parte del incumplimiento total, pero no se agota allí. También habría que tomar en consideración el régimen de saneamiento de los vicios redhibitorios, aun cuando fuerza aceptar que la coicidencia no es plena.

No se han explicado las anomalías de cantidad del artículo 19, ni la concepción del vicio que nace por las declaraciones publicitarias que efectúa el vendedor o incluso un tercero, que también forman parte del contrato transformándose en una prestación exigible para el consumidor (artículo 20 letra c). Por tales razones, todo indicaría que el supuesto de hecho que activa la protección del consumidor, más bien se acercaría a la noción de falta de conformidad contemplada en la Convención de Viena sobre compraventa internacional de mercaderías, texto de la República desde 1990, y los demás instrumentos contractuales de derecho uniforme, especialmente la Directiva 44/99/CE sobre determinados aspectos de la venta y las garantías de los bienes de consumo ${ }^{42}$.

42 Caprile Biermann, Bruno (2008) "Las acciones del comprador insatisfecho: el cúmulo actual (ley de protección al consumidor, vicios redhibitorios, error sustancial, resolución por incumplimiento) y la tendencia al deber de conformidad en el derecho comparado". Coordinadores Fabricio Mantilla Espinosa y Carlos Pizarro Wilson. Estudios de Derecho privado en homenaje a Christián Larroumet. Santiago: Editorial Fundación Fueyo-Universidad Diego Portales, pp. 561-602, y Caprile Biermann, Bruno (2007) "Las acciones del comprador insatisfecho: el cúmulo actual y la tendencia al deber de conformidad”. Coordinadores Hernán Corral y María Sara Rodríguez. Estudios de Derecho Civil II. Santiago: LexisNexis, pp. 629-650; Vidal Olivares, Álvaro (2007b) "El incumplimiento de obligaciones con objeto 


\section{CONCLUSIONES}

En primer lugar, es posible concluir que no sería adecuado reconducir el incumplimiento de la garantía legal a alguna de las tipologías tradicionales que describe el artículo 1556 CC.

Si bien el derecho de opción guarda ciertas correspondencias con la inejecución total por falta de entrega, y se acerca al concepto de vicio redhibitorio, hay que concluir que excede con creces esta clasificación. En efecto, contiene el aliud pro alio en su versión de las faltas de especificaciones, sea en las normas de cumplimiento obligatorio, en las menciones que ostente el producto, o en las especificaciones convenidas con el consumidor, pero además regula las anomalías de cantidad y el efecto de las declaraciones publicitarias disconformes.

Desde el punto de vista del obligado a responder, cabe concluir que la garantía legal también se aprecia como una institución más eficaz que las acciones de saneamiento de los vicios redhibitorios, por cuanto permite al consumidor accionar contra el vendedor. Asimismo, en sede de consumo es posible exigir la reparación de forma directa al fabricante, e incluso se contemplan acciones contra el importador a través de un régimen solidario de responsabilidad.

Si se examinan los remedios que ofrece el sistema civil y de consumo, igualmente se ven divergencias. La acción redhibitoria (sea resolutoria o anulatoria) y la rebaja del precio contemplada en los artículos 1857 y siguientes CC solo contemplan formas de quiebre del vínculo obligacional, mientras que la ley de consumo recoge acciones de cumplimiento. La reparación y sustitución de los artículo 19 y 20 LPDC son remedios irrenunciables eficaces para el consumidor que necesita los bienes de consumo masivo.

Así las cosas, conviene estudiar el incumplimiento que activa la garantía legal desde la perspectiva de la conformidad o falta de conformidad contemplada en los instrumentos de armonización del derecho contractual europeo, que, en aras de la unificación, han acogido una noción amplia y unitaria, que cuenta con un sistema de remedios articulado en torno él, tal como existiría en nuestra LPDC.

\section{BIBLIOGRAFÍA}

- Abeliuk Manasevich, René (2010) Las obligaciones. $5^{a}$ edición actualizada y aumentada. Santiago: Editorial Jurídica de Chile.

fungible y los remedios del acreedor afectado. Una relectura de las disposiciones del 'Código Civil' sobre incumplimiento”. Editor científico Alejandro Guzmán Brito. El Código Civil de Chile (1855-2005). Santiago: LexisNexis, pp. 495-550. 
- Alessandri Rodríguez, Arturo (2003) De la compraventa y de la promesa de compraventa, tomo I volumen No 2. Santiago: Editorial Jurídica de Chile.

- Bahamondes Oyarzún, Claudia (2011) "Concurrencia de la indemnización de perjuicios de daños y la pretensión de cumplimiento específico frente al incumplimiento". Coordinador Ińigo de la Maza. Incumplimiento contractual. Nuevas perspectivas. Cuadernos de análisis jurídicos. Colección de Derecho Privado VII, Santiago: Ediciones Universidad Diego Portales, pp. 235-264.

- Baraona González, Jorge (2008) "Algunas consideraciones sobre el retraso en el cumplimiento de las obligaciones: su configuración y eficacia". Coordinador Carlos Pizarro Wilson. Estudios de Derecho Civil IV. Santiago: Editorial LegalPublishing, pp. 372-374.

- Baraona GonzÁlez, Jorge (2008) "La acción redhibitoria como acción de nulidad". Editor científico Alejandro Guzmán Brito. Estudios de Derecho Civil III. Santiago: Editorial LegalPublishing, pp. 659-669.

- Barros Bourie, Enrique (2008) "Finalidad y alcance de las acciones y remedios contractuales". Editor científico Alejandro Guzmán Brito. Estudios de Derecho Civil III. Santiago: LegalPublishing, pp. 403-428.

- Caprile Biermann, Bruno (2008) "Las acciones del comprador insatisfecho: el cúmulo actual (ley de protección al consumidor, vicios redhibitorios, error sustancial, resolución por incumplimiento) y la tendencia al deber de conformidad en el derecho comparado. Coordinadores Fabricio Mantilla Espinosa y Carlos Pizarro Wilson. Estudios de Derecho privado en homenaje a Christián Larroumet. Santiago: Editorial Fundación Fueyo-Universidad Diego Portales, pp. 561-602.

- Caprile Biermann, Bruno (2007) "Las acciones del comprador insatisfecho: el cúmulo actual y la tendencia al deber de conformidad". Coordinadores Hernán Corral y María Sara Rodríguez. Estudios de Derecho Civil II. Santiago: LexisNexis, pp. 629-650.

- Claro Solar, Luis (1937) Explicaciones de Derecho Civil chileno y comparado, t. XI. De las obligaciones II. Santiago: Editorial Nascimento.

- Corral Talciani, Hernán (2006) "La responsabilidad por incumplimiento y por productos peligrosos en la ley de protección de los derechos de los consumidores". Editores Jorge Baraona y Osvaldo Lagos. Cuadernos de extensión Jurídica. La protección de los derechos de los consumidores en Chile. Aspectos sustantivos y procesales luego de la reforma contenida en la Ley $N^{\circ} 19.955$ de 2004, $N^{\circ} 12$, Santiago: Ediciones Universidad de los Andes, pp. 95-110. 
- Corral Talciani, Hernán (1999) "Ley de protección al Consumidor y responsabilidad civil". Editor Hernán Corral. Derecho del consumo y protección al consumidor. Estudios sobre la Ley $N^{o} 19.496$ y las principales tendencias extranjeras. Cuadernos de Extensión Jurídica $N^{o}$ 3. Santiago: Ediciones Universidad de los Andes, pp. 163-211.

- De la Maza Gazmuri, Iñigo (2012) "El régimen de los cumplimientos defectuosos en la compraventa". Revista chilena de Derecho privado. Volumen 39, No 3, pp. 629-663.

- De la Maza Gazmuri, Ińigo (2011) "El concurso entre el error con transcendencia anulatoria y el incumplimiento resolutorio". Coordinador Iñigo de la Maza. Incumplimiento contractual. Nuevas perspectivas. Cuadernos de análisis jurídicos. Colección de Derecho Privado VII, Santiago: Ediciones Universidad Diego Portales, pp. 213-234.

- De la Maza Gazmuri, Iñigo (2010) "A propósito del artículo 1861". Editores Departamento de Derecho Privado Universidad de Concepción. Estudios de Derecho Civil V. Santiago: Editorial LegalPublishing, pp. 455-469.

- De la Maza Gazmuri, Ińigo (2009) Ofertas sujetas a reserva: a propósito de los términos y condiciones en los contratos celebrados por medios electrónicos. Revista de Derecho. Volumen XXII. Año N ${ }^{\circ}$ 2, pp. 75-95.

- De Verda y Beamonte, José Ramón (2009) Saneamiento por vicios ocultos. Las acciones edilicias, $2^{\text {a }}$ edición. Navarra: Editorial AranzadiThomson Reuters.

- Díez Duarte, Raúl (1993) La compraventa en el Código Civil chileno. $2^{\text {a }}$. edición actualizada. Santiago: Editorial Jurídica ConoSur.

- Figueroa Yáñez, Gonzalo (2004) "El efecto relativo en los contratos conexos". Coordinadora María Dora Martinic, Nuevas tendencias del Derecho,. Santiago: Editorial LexisNexis, pp. 67-81.

- Fueyo Laneri, Fernando (2004) Cumplimiento e incumplimiento de las obligaciones. Actualizado por Figueroa Yáñez, Gonzalo. Santiago: Editorial Jurídica de Chile.

- Guzmán Brito, Alejandro (2007) "Sobre la relación entre las acciones de saneamiento de los vicios redhibitorios y las acciones comunes de indemnización, con especial referencia a la prescripción”. Revista chilena de Derecho Privado, No 9, pp. 95-119.

- López DíAz, Patricia (2010) "La indemnización compensatoria por incumplimiento de los contratos bilaterales como remedio autónomo en el derecho civil chileno". Revista Chilena de Derecho privado, No 15, pp. 65-113. 
- Mejías Alonzo, Claudia (2011) El incumplimiento resolutorio en el Código Civil. Santiago: Editorial AbeledoPerrot-LegalPublishing.

- Morales Moreno, Antonio Manuel (2006) "Adaptación del Código Civil al derecho europeo: la compraventa". La modernización del Derecho de las obligaciones. Madrid: Editorial Thomson Civitas, pp. 93-144.

- Nieto Alonso, Antonia (2003) "La responsabilidad por vicios o defectos ocultos en las ventas. La superación de la rígida normativa del Código Civil como medio de defensa de los consumidores y usuarios". Comité organizador Antonio Cabanillas Sánchez et alii. Estudios jurídicos en homenaje al profesor Luis Diez-Picazo. Madrid: Editorial Thomson Civitas, pp. 2695-2714.

- Pizarro Wilson, Carlos (2008) "Hacia un sistema de remedios al incumplimiento contractual". Editor científico Alejandro Guzmán Brito. Estudios de Derecho Civil III. Santiago: LegalPublishing, pp. 395-402.

- Pizarro Wilson, Carlos (2007) "El efecto relativo de los contratos: partes y terceros". Editor científico Alejandro Guzmán Brito. El Código Civil de Chile. Santiago: Editorial LexisNexis, 2007, pp. 551567.

- Vidal Olivares, Álvaro (2011) "La indemnización de daños y la opción del acreedor frente al incumplimiento". Coordinadores Gonzalo Figueroa Yáñez et alii. Estudios de Derecho Civil VI. Santiago: Editorial AbeledoPerrot LegalPublishing. pp. 763-780.

- Vidal Olivares, Álvaro (2009) "La noción de incumplimiento esencial en el 'Código Civil'”. Revista de Derecho, XXXII, pp. 221-258.

- Vidal Olivares, Âlvaro (2007a) "La pretensión de cumplimiento específico y su inserción en el sistema de remedios por incumplimiento en el Código Civil”. Coordinadores Hernán Corral y María Sara Rodríguez. Estudios de Derecho Civil II. Santiago: LexisNexis, pp. 517-538

- Vidal Olivares, Álvaro (2007b) "El incumplimiento de obligaciones con objeto fungible y los remedios del acreedor afectado. Una relectura de las disposiciones del 'Código Civil' sobre incumplimiento”. Editor científico Alejandro Guzmán Brito. El Código Civil de Chile (1855-2005). Editorial LexisNexis: Santiago, pp. 495-550.

\section{JURISPRUDENCIA}

- Corte de Apelaciones de San Miguel, 10 de mayo de 2011, Rol No 195-2011, LegalPublishing No 49281, "Méndez con París S.A.", disponible en www.westlaw.cl [fecha de visita 01 de marzo de 2013]. 
- Corte de Apelaciones de Coyhaique, 05 de mayo de 2011, Rol No 8-2011, LegalPublishing No 49328, "San Martin, Sernac con ABC Din", disponible en www.westlaw.cl [fecha de visita 05 de marzo de 2013].

- Corte de Apelaciones de Santiago, 12 de marzo de 2012, Rol No 8470-2010 y Juzgado de Policía Local de Vitacura, 11 de noviembre de 2009, Rol No 114.876 "Campos con Dell computer de Chile Ltda.", disponible en www.poderjudicial.cl [fecha de visita 08 de marzo de 2013].

- Corte de Apelaciones de Concepción, 01 de diciembre de 1993, Rol No 1171-1992, LegalPublishing No 22097), "Transportes Sierra Nevada con Dosque", www.westlaw.cl [fecha de visita 08 de marzo de 2013]

- Corte Suprema, 27 de julio de 2005, Rol No 5320-2003, Legal Publishing 32452, "Comercial Salinak con Cecinas La Preferida", www.westlaw.cl [fecha de visita 10 de enero de 2013].

- Corte Suprema, 31 de octubre de 2012, 3325-2012, Cita Westlaw CL/JUR/2412/2012, Zorín S.A. con Compañía Siderúrgica Huachipato", www.westlaw.cl [fecha de visita 10 de enero de 2013].

- Corte de Apelaciones de Antofagasta, 29 de octubre de 2008, Rol No 107-2008, LegalPublishing No 40448, "Morales con Homecenter Sodimac", www.westlaw.cl [fecha de visita 10 de enero de 2013].

- Corte de Apelaciones de Arica, 16 de abril de 2011, Rol No 142011, LegalPublishing No 49244, "Vergara con Empresa de Correos de Chile", www.westlaw.cl [fecha de visita 10 de enero de 2013].

- Corte de Apelaciones de Rancagua, 21 de octubre de 2008, Rol No 828-2007, LegalPublishing No 38231, "Aravena con Comercial Rupanco Limitada e Inversiones San Ignacio S.A.”, www.westlaw.cl [fecha de visita 20 de enero de 2013].

- Corte Suprema, 24 de mayo de 2007, Rol No 3140-2005, MJJ: 9854, "Varela y otros con Servicio de Vivienda y Urbanismo I Región”, www.microjuris.cl [fecha de visita 20 de enero de 2013].

- Corte Suprema, 25 de julio de 2007, Rol No 6658-2007, LegalPublishing No 36814, "Spataris con Sociedad Comercial Automotriz La Portada con Luna" www.westlaw.cl, [fecha de visita 02 de marzo de 2013]

- Corte Suprema, 8 de julio de 2010, Rol No 8115-2010, MJJ: 24291, "AGF Allianz Chile compañía de seguros generales S.A. con Le Torneau Inc.", www.microjuris.cl [fecha de visita 20 de enero de 2013]

- Corte Suprema, 25 de mayo de 2010, Rol No 5849-2008, MJJ: 24029, "Fernández con E. Kovakcs S.A." www.microjuris.cl [fecha de visita 20 de enero de 2013] 
- Corte Suprema, 27 de marzo de 2008, Rol No 6700-2006, LegalPublishing No 38680, "Larzabal con Sociedad Inmobiliaria Talasia Limitada", www.westlaw.cl, [fecha de visita 02 de marzo de 2013]

- Corte Suprema, 14 de noviembre de 2006, Rol No 2265-2006, LegalPublishing No 35531, "Jara y varios con Sociedad inmobiliaria San Francisco Limitada" www.westlaw.cl, [fecha de visita 02 de marzo de 2013]. 